\title{
The Permissive Cue Laminin Is Essential for Growth Cone Turning In Vivo
}

\author{
Jennifer Bonner and Timothy P. O'Connor \\ Department of Anatomy, Program in Neuroscience, University of British Columbia, Vancouver, British Columbia, Canada \\ V6T $1 Z 3$
}

\begin{abstract}
The proper guidance of migrating growth cones relies on the balance of multiple guidance cues in the embryonic environment. In addition to guidance cues, growth cones are in contact with other substrates that may contribute to the pathfinding of neurons. For example, in the developing insect peripheral nervous system, pioneer neurons migrate on and between layers of the basal lamina. Previous studies have demonstrated that one basal lamina molecule, laminin, promotes outgrowth of many classes of neurons in vitro. In this study, the simple grasshopper nervous system was used to investigate the role of laminin in neuronal pathfinding. Laminin expression precedes axonogenesis of the Tibial (Ti1) pioneer neurons in the developing limb bud, and expression continues during outgrowth and guidance of the pioneer neurons. The role of a nidogen-
\end{abstract}

binding motif on laminin was investigated using subunitspecific antibodies and peptides as blocking reagents in vivo. Antibodies and peptides that block the nidogen-binding site on laminin resulted in stalled Ti1 axon migration, predominantly at the precise location where they normally turn ventrally. After prolonged culturing, Ti1 axons remained stalled at the same location. Therefore, although Ti1 axons were capable of outgrowth in the presence of blocking reagents, they were not able to navigate an essential turn. This study indicates that the interaction of the Ti1 growth cone with the nidogen-binding site on laminin is vital for neuronal pathfinding in vivo and suggests that permissive cues may be essential for growth cone steering.

Key words: laminin; growth cone turning; permissive cues; axon guidance; grasshopper; in vivo
A growing axon encounters many cues in the embryonic environment that are processed by the growth cone and result in directed outgrowth. These cues can be considered instructive or permissive. Instructive cues generally have a restricted expression pattern and guide neurons by conferring either attractive or inhibitory information on the growth cone, leading to reorganization of the cytoarchitecture that culminates in a steering event. Growth cones may also encounter permissive cues as they steer in response to instructive cues. However, it is unclear whether permissive cues aid in the decision making of growth cones. Recent work has indicated that the stimulus history of a neuron affects responsiveness to upcoming cues (Shirasaki et al., 1998; Matise et al., 1999; Diefenbach et al., 2000). This could be one mechanism by which permissive cues act on migrating neurons; however, this has not been demonstrated in vivo.

A variety of permissive cues can be found in the basal lamina, which is a complex array of many different proteins, including laminin, type IV collagen, nidogen, and perlecan (Timpl and Brown, 1996). Laminin is a major component of the basal lamina and consists of three subunits, $\alpha, \beta$, and $\gamma$. The three subunits are secreted as a trimer and can self-assemble to form polymeric

\footnotetext{
Received May 18, 2001; revised Aug. 30, 2001; accepted Oct. 2, 2001.

This work was funded by a Rick Hansen Institute Neurotrauma Initiative studentship to J.B., by Rick Hansen Institute Neurotrauma Initiative Grant 99019 to T.P.O., and by Canadian Institutes of Health Research Grant 13246 to T.P.O. T.P.O. is an EJLB Research Scholar. We gratefully acknowledge Sal Carbonetto for $\beta 1$-integrin antibodies, Kim Gerrow for providing limb fillets, and Ken Norman for confocal expertise. In addition, we thank Katharine Sepp and Joost Schulte for critical reading of this manuscript.

Correspondence should be addressed to Timothy P. O'Connor, Department of Anatomy, Program in Neuroscience, University of British Columbia, 2177 Wesbrook Mall, Vancouver, British Columbia, Canada V6T 1Z3. E-mail: jimo@ interchange.ubc.ca.

Copyright (C) 2001 Society for Neuroscience $\quad 0270-6474 / 01 / 219782-10 \$ 15.00 / 0$
}

sheets (Timpl and Brown, 1996). Genetic analysis of laminin function reveals that laminin is required for basal lamina stability (Noakes et al., 1995; Garcia-Alonso et al., 1996; Miner and Li, 2000). Therefore, testing laminin function in axon guidance in a genetic system is problematic, considering its widespread involvement in developmental events. Because of these experimental constraints, the role of laminin in directing neurons during development in vivo has been difficult to address.

Several studies have implicated laminin as a potent promoter of neurite outgrowth in vitro (for review, see Powell and Kleinman, 1997), as a directional cue for migrating axons in vitro (Kuhn et al., 1995; Halfter, 1996; Kuhn et al., 1998), and as an important guidance molecule for developing axons in vivo (Garcia-Alonso et al., 1996; Forrester and Garriga, 1997). One class of laminin receptors, the integrins, are critical in mediating laminin-induced neurite outgrowth (for review, see Powell and Kleinman, 1997) and are modulated depending on laminin availability (Condic and Letourneau, 1997), laminin conformation (Calof et al., 1994; Ivins et al., 1998), and developmental age (Cohen et al., 1986, 1989; Hall et al., 1987; Ivins et al., 2000). This suggests dynamic interplay between laminin and integrins on the neuronal cell surface.

In this study, we examine the role of the permissive cue laminin in axon guidance. Sequence analysis of the grasshopper laminin $\gamma$-chain demonstrates a single conserved nidogenbinding site that has been shown to be important for epithelial tissue morphogenesis in other systems (Gerl et al., 1991; Mayer et al., 1993a; Ekblom et al., 1994; Poschl et al., 1996; Kadoya et al., 1997). We show that this nidogen-binding site is important for axonal pathfinding and may be required for growth cone turning in vivo. 


\section{MATERIALS AND METHODS}

Antibody staining. Embryos were dissected out of their egg cases in saline, and the amnion was removed and staged according to the method of Bentley et al. (1979). Embryos were fixed for $1 \mathrm{hr}$ in $3.7 \%$ formaldehyde in PIPES, EGTA, and $\mathrm{MgSO}_{4}$. Embryos were blocked for $1 \mathrm{hr}$ at $4^{\circ} \mathrm{C}$ in either PBT and 5\% normal goat serum or PBT and 5\% normal donkey serum, depending of the host of the secondary antibody. Primary antibodies (see below) were incubated overnight at $4{ }^{\circ} \mathrm{C}$, followed by several washes in PBS supplemented with $0.1 \%$ bovine serum albumin and $0.1 \%$ Triton X-100, pH 7.2 (PBT) and secondary antibody incubation at 1:250 in PBT for $1 \mathrm{hr}$ at room temperature. Embryos were again washed in PBT and mounted in Slowfade antifade (Molecular Probes, Eugene, OR). Primary antibody concentrations were as follows: goat anti-HRP, 1:500; rabbit anti-HRP, 1:500; rabbit anti-laminin $\gamma$-chain, 1:500; rabbit antisemaphorin 2a, 1:250; mouse anti-semaphorin 1a, 1:1; rabbit anti- $\beta$ integrin (against the full-length protein), 1:20; and rabbit anti- $\beta$ integrin (against the intracellular domain), 1:50. Rabbit anti- $\beta$-integrin antibodies were courtesy of Salvatore Carbonetto (McGill University, Montréal, Québec, Canada). Goat anti-HRP and rabbit anti-HRP were from Jackson ImmunoResearch (West Grove, PA), as were the secondary antibodies used in this study (FITC-conjugated donkey anti-goat, FITCconjugated donkey anti-rabbit, Cy3-conjugated goat anti-mouse, and FITC-conjugated goat anti-rabbit). For double labeling, primary antibodies were incubated together with embryos overnight at $4^{\circ} \mathrm{C}$. Secondary antibodies were also incubated together for $1 \mathrm{hr}$ at room temperature. For integrin immunofluorescence, embryos were immobilized on glass coverslips previously coated in $5 \mathrm{mg} / \mathrm{ml}$ poly-L-lysine and filleted along the proximal-distal axis of the limb (O'Connor et al., 1990). Filleted limbs were rolled open to expose the ventral epithelium, containing the Tibial (Ti1) neurons. Embryos were fixed and stained with anti- $\beta 1$ integrin antibodies.

Confocal microscopy. Confocal immunofluorescent images were collected on a Nikon Optiphot-2 microscope using an MRC 600 confocal system (Bio-Rad, Hercules, CA) equipped with a krypton-argon laser. The images collected from the confocal microscope were captured in a $768 \times 512$ pixel field of view with the optical sections collected at $0.8 \mathrm{~mm}$ intervals. The confocal images were composed of 100-150 optical sections for each embryo. Data collected from the confocal microscope were analyzed in NIH Image 1.61, and Adobe (Mountain View, CA) Photoshop 4.0 was used for presentation. Confocal microscopy was conducted at the Electron Microscopy facility at the University of British Columbia.

IgG purification. The IgG fraction of immune and preimmune sera was isolated using an Immunopure protein A IgG orientation kit (Pierce, Rockford, IL). Sera were loaded onto columns and the columns were washed with $4 \times 5 \mathrm{ml} 1 \mathrm{M} \mathrm{NaCl}$. The IgG fraction was eluted with $0.1 \mathrm{M}$ glycine, $\mathrm{pH} 2$, and neutralized with $100 \mu \mathrm{l}$ of $1 \mathrm{~m}$ Tris, $\mathrm{pH}$ 7.5. Absorbance at $280 \mathrm{~nm}$ was taken, and the concentration was determined using the equation $1 \mathrm{OD}=0.75 \mathrm{mg} / \mathrm{ml}$ protein.

Dialysis. Before culturing, preimmune and immune $\mathrm{IgG}$ fractions were dialyzed against sterile RPMI medium overnight at $4^{\circ} \mathrm{C}$. The $\mathrm{IgG}$ fractions were placed in $6-8 \mathrm{kDa}$ dialysis tubing, which was placed in $500 \mathrm{ml}$ of sterile RPMI medium. After overnight incubation, the medium was refreshed once, and dialysis continued for another $5 \mathrm{hr}$.

Western blot analysis of fusion proteins. Fifty nanograms of purified fusion protein was electrophoresed at $200 \mathrm{~V}$ in a $7.5 \%$ SDS-PAGE gel (4\% stacking gel) and electrotransferred to Hybond enhanced chemiluminescence (ECL) nitrocellulose (Amersham Pharmacia Biotech, Arlington Heights, IL). Transfer buffer consisted of $25 \mathrm{~mm}$ Tris, $192 \mathrm{~mm}$ glycine, and $20 \%$ methanol. The blots were blocked in $5 \%$ milk powder, PBS, and $0.1 \%$ Tween 20 overnight at $4^{\circ} \mathrm{C}$. Primary antibody was used at a dilution of 1:10,000 for $\beta$ and $\gamma$ antisera and $\beta$ and $\gamma$ preimmune sera in $1 \%$ milk powder, PBS, and $0.1 \%$ Tween 20 . Primary antibody incubations were conducted at room temperature for $2 \mathrm{hr}$, followed by washes in PBS and $0.1 \%$ Tween 20. Secondary antibodies (HRP-conjugated goat anti-rabbit) were diluted to $1: 1500$ in PBS and 0.1\% Tween 20 and incubated for $1 \mathrm{hr}$ at room temperature. After washes in PBS and $0.1 \%$ Tween 20, blots were reacted in ECL detection buffer (Amersham Pharmacia Biotech), and exposed to X-OMAT x-ray film (Eastman Kodak Co., Rochester, NY).

Western blot analysis of embryonic lysate. Approximately 50 grasshoppers at $35-40 \%$ of development were dissected from their egg cases in saline and resuspended in $1 \times$ radioimmunoprecipitation assay buffer (with $85 \mu \mathrm{g} / \mathrm{ml}$ PMSF, $0.5 \mu \mathrm{g} / \mathrm{ml}$ aprotinin, and $1 \mu \mathrm{g} / \mathrm{ml}$ leupeptin). Embryos were centrifuged at $14,000 \mathrm{rpm}$ at $4^{\circ} \mathrm{C}$ for $20 \mathrm{~min}$, and supernatant was retained. Western blot analysis was performed as with fusion protein with the following exceptions: embryonic lysates were electrophoresed on a $6 \%$ SDS-PAGE gel (4\% stacking gel) overnight at $20 \mathrm{~V}$ at $4^{\circ} \mathrm{C}$; and the gel was electrotransferred to nitrocellulose in $50 \mathrm{~mm}$ Tris, $380 \mathrm{~mm}$ glycine, and $0.1 \%$ SDS at $30 \mathrm{~V}$ overnight at $4^{\circ} \mathrm{C}$. The rest of the Western blot analysis was performed as in the protocol for the fusion protein Western blot analysis.

Culturing. Eggs were sterilized in $70 \%$ ethanol and rinsed twice in sterile grasshopper culture media (RPMI medium, $4 \mu \mathrm{M} 20$ hydroxyecdysone, $0.4 \mathrm{~mm} \mathrm{CaCl}{ }_{2}, 0.4 \mathrm{mM} \mathrm{MgSO}_{4}, 2 \mathrm{U} / \mathrm{ml}$ insulin, 100 $\mathrm{U} / \mathrm{ml}$ penicillin, $100 \mu \mathrm{g} / \mathrm{ml}$ streptomycin, $10 \%$ heat-inactivated FBS, 2 $\mathrm{mm}$ L-glutamine, $0.45 \mathrm{~mm}$ sodium pyruvate, $1 \mathrm{~mm}$ oxaloacetic acid, $0.45 \%$ D-glucose, and $0.12 \mathrm{~m}$ sucrose, $\mathrm{pH}$ 6.9). Embryos were dissected as before (see Antibody staining) in grasshopper culture media. Embryos were cultured in the presence of blocking peptides or antibodies. For longer cultures, embryos were prepared as described for culturing but with the following modifications: after $24 \mathrm{hr}$ in culture, the medium was removed, and fresh medium was added, with the appropriate blocking reagents.

Blocking peptides. The DPNAV peptide was designed on the basis of grasshopper laminin deduced amino acid sequences. As a control, randomly scrambled peptides were used (PANDV for DPNAV). All peptides were generated at the Protein Services Unit at the University of British Columbia and dissolved in sterile $\mathrm{H}_{2} \mathrm{O}$. DPNAV and PANDV were used at a final concentration of $0.2 \mathrm{mg} / \mathrm{ml}$.

Blocking antibodies. A 561 bp EcoRI fragment of domain III of the $\gamma$ chain of laminin was subcloned into EcoRI-cut pGEX 2T (Amersham Pharmacia Biotech). pGEX-specific primers were used to sequence clones to confirm cloning junctions with respect to orientation and frame. Glutathione $S$-transferase fusion proteins were purified with glutathionelinked agarose beads (Sigma, St. Louis, MO) according to the method of Smith and Johnson (1988).

Rabbits were initially injected with $0.5 \mathrm{mg}$ of fusion protein in $500 \mu \mathrm{l}$, which was emulsified with an equal volume of Freund's complete adjuvant (Sigma). For all subsequent injections, $0.1 \mathrm{mg}$ of protein in $500 \mu \mathrm{l}$ was emulsified with an equal volume of Freund's incomplete adjuvant (Sigma). Rabbits were housed and cared for at the University of British Columbia Animal Care Center. All bleeds were processed according to the method of Harlow and Lane (1988).

All antibodies, including preimmune controls, were prepared as follows: $\operatorname{IgG}$ was isolated from sera and dialyzed against sterile RPMI; $\gamma$ antisera and preimmune sera were used at $1 \mu \mathrm{M}$, as determined by an $A_{280}$ spectrophotometric reading.

Assessment of basal lamina integrity in blocked embryos. Embryos were cultured in the presence of the DPNAV peptide for $24 \mathrm{hr}$ as described. After the culture period, embryos were fixed and stained for HRP and semaphorin 2a immunoreactivity and HRP and laminin $\gamma$ antisera immunoreactivity. Embryos were processed for confocal microscopy as described above.

\section{RESULTS}

\section{Laminin expression is evenly distributed during development of the Ti1 pathway}

In the developing limb bud, the Ti1 pioneer sensory neuron projection establishes a projection to the CNS by $35 \%$ of embryonic development. The pathway is stereotyped and consists of a series of sequential steering decisions (Keshishian and Bentley, 1983). At $30 \%$ of embryonic development, the newly formed Ti1 neurons delaminate from the epithelium and extend axons proximally toward the CNS (Fig. 1 $A$ ). After the initial proximal extension of the Ti1 axons, the Ti1 growth cones contact a preaxonogenesis neuron, the Fe1 (femur 1) cell, at $\sim 32 \%$ and continue proximal growth (Fig. 2B). Subsequently, at $33 \%$ of development, the Ti1 axons contact a second preaxonogenesis cell, the Tr1 (trochanter 1) cell (Fig. 2D). On contact with this cell, the Ti1 axons make a ventral turn along the trochanter epithelium (Fig. $2 F$ ). After migrating ventrally in the trochanter epithelium, the growth cones contact another intermediate target, the Cx1 (Coxa-1) neurons, and turn proximally, extending into the CNS (Fig. 2H; Keshishian and Bentley, 1983). Later in development, the Ti1 pathway prefigures the migratory paths of 

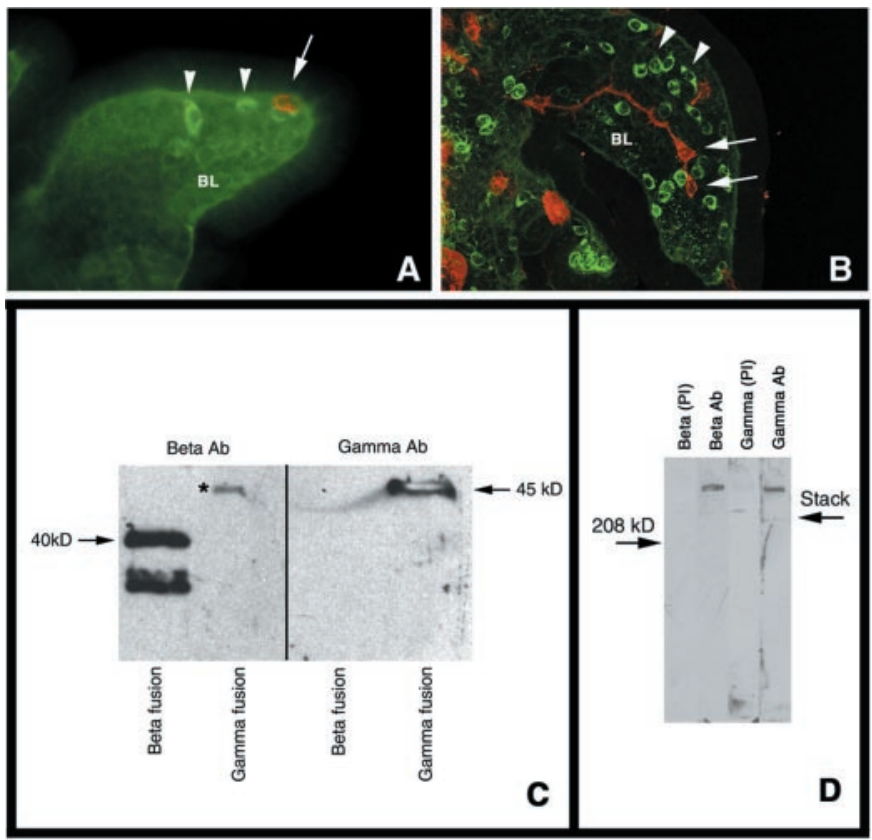

Figure 1. Laminin is expressed by hemocytes at 30 and $35 \%$ of embryonic development in the grasshopper limb bud. $A, B$, Immunofluorescent images of grasshopper limb buds at $30 \%(A)$ and $35 \%(B)$ of development that are double-labeled with laminin $\gamma$ antisera (green) and HRP (red). $A$, Ti1 neurons emerge from the surrounding epithelium at $30 \%$ of development (arrow) in a basal lamina $(B L)$ that is rich in laminin. Laminin-expressing hemocytes are visible in the limb (arrowheads). B, Confocal image of a limb bud at 35\% of embryonic development. The Ti1 pathway (red) has been established, and arrows point to the Ti1 cell bodies, which have separated slightly in this limb. Laminin immunoreactivity in the basal lamina is even, and lamininexpressing hemocytes (arrowheads) are abundant. $C$, Western blot analysis of laminin $\beta$ and $\gamma$ glutathione $S$-transferase fusion proteins with $\beta$ and $\gamma$ antibodies. Laminin $\gamma$ antiserum is specific for the $\gamma$ fusion protein but does not recognize the $\beta$-chain fusion protein, whereas $\beta$-chain antibodies cross-react with $\gamma$-chain fusion protein (asterisk). D, Western blot analysis of lysate from embryos at $40 \%$ of development with $\beta$ and $\gamma$ antibodies and preimmune sera $(P I)$. Both $\beta$ and $\gamma$ antisera recognize a high molecular weight complex (polymerized laminin) in the stacking gel. The $\beta$ and $\gamma$ antibodies recognize a similarly sized band. Preimmune serum reacts with no bands. Scale bar, $10 \mu \mathrm{m}$.

later-arising neurons. As the Ti1 growth cones migrate, they make contact with several substrates, including the laminin-rich basal lamina (Anderson and Tucker, 1989), epithelium, and several intermediate neuronal targets (Keshishian and Bentley, 1983; O'Connor, 1999).

To determine the specificity of the laminin $\gamma$-chain antibodies, Western blots were conducted. Sera raised against epidermal growth factor (EGF) repeats of the $\gamma$-chain of laminin reacted with $\gamma$ fusion protein (Fig. $1 C$ ) but not with a fusion protein of EGF repeats from the $\beta$-chain (Fig. $1 C$ ). On grasshopper embryonic lysates, both the $\gamma$ antisera and the sera raised against the EGF repeats of the $\beta$-chain recognize the same high molecular weight band (Fig. $1 D$ ) that represents the laminin heterotrimer. The $\beta$ and $\gamma$ antibodies also react with purified laminin (see Materials and Methods) on a Western blot (data not shown), and these bands were of a size comparable with that of the grasshopper laminin bands.

The antibodies generated against the laminin chains were used to determine laminin distribution during Ti1 migration, from 30
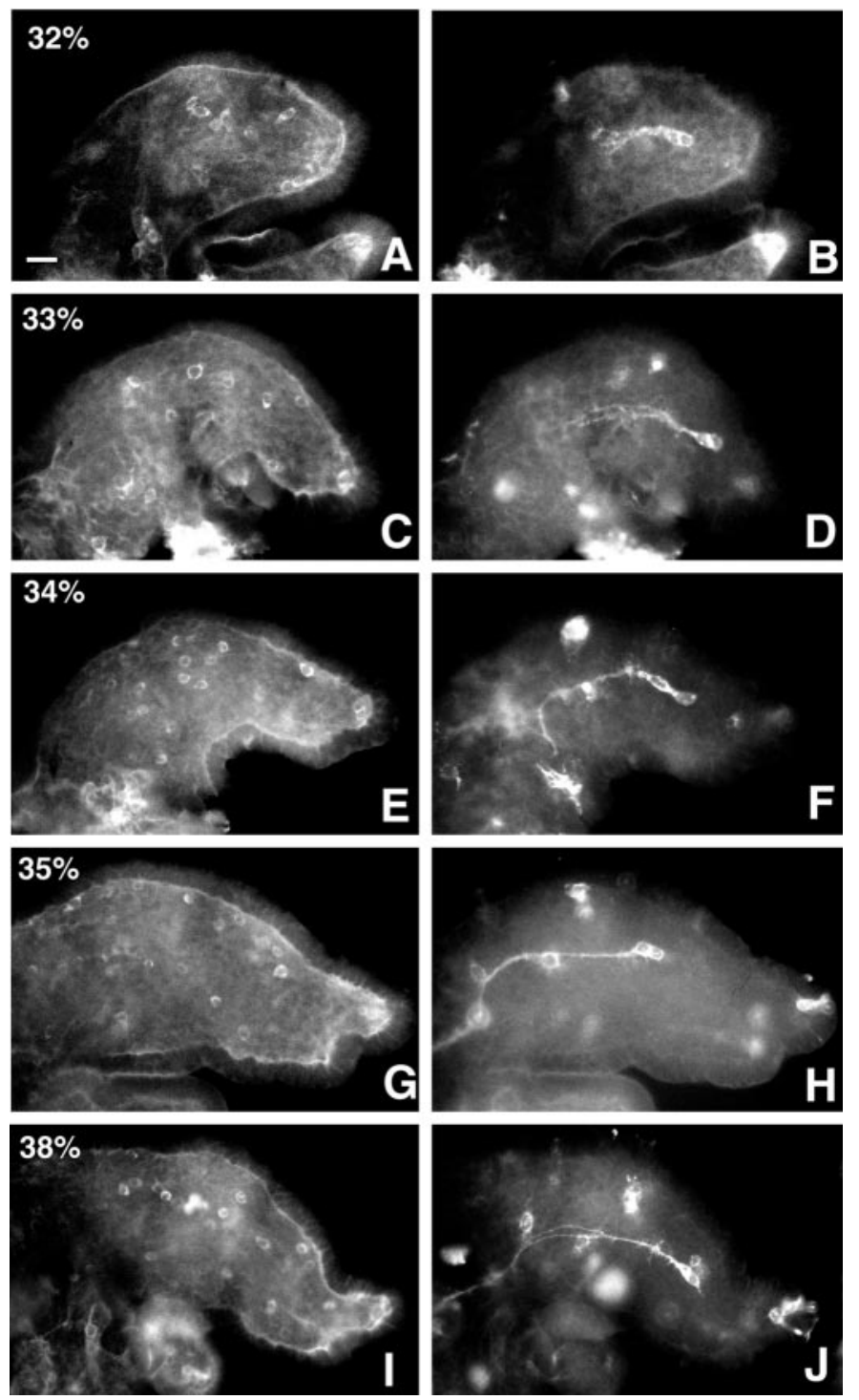

Figure 2. Time course of laminin expression in relation to the Ti1 pioneer neuron pathway. Immunofluorescence of laminin (left) and HRP (right) is shown. From 32 to $38 \%$ of development, laminin is expressed evenly in the basal lamina during the time that the Ti1 pathway is established. Scale bar, $20 \mu \mathrm{m}$.

to $35 \%$ of embryonic development. At $30 \%$ of development, Ti1 neurons have delaminated from the epithelium, and an even expression of laminin in the basal lamina is already established (Fig. $1 A$ ). In certain preparations, laminin appeared concentrated in the distal tip of the limb, for example, in Figure $2 A, G, I$. However, Ti1 growth cones appeared to migrate only through regions of uniform laminin distribution as they extended toward the CNS (Fig. 2). Throughout the duration of Ti1 migration, from 30 to $35 \%$ of development, laminin is evenly distributed in the basal lamina (Figs. $1 A, B, 2 A-H$ ). At $38 \%$ of development, laterarising "follower" neurons begin to migrate toward the Ti1 pathway. At this time in development, laminin is also evenly expressed, (Fig. 2I,J), suggesting a similar role of laminin in guidance of pioneer neurons as well as follower neurons. In addition to being found in the basal lamina, laminin protein (as well as mRNA; data not shown) is also detected in migrating hemocytes (Figs. 1A, $B, 2$ ). Laminin deposition in the basal lam- 
ina is achieved by high expression of laminin in randomly migrating hemocytes, which secrete laminin as they migrate throughout the limb (our unpublished results).

\section{Localization of laminin receptors on Ti1 growth cones and axons}

Laminin is a major component of the basal lamina that is expressed dynamically during development, as early as the 2- to 4-cell stage in mouse, whereas nidogen is not detected until the 8to 16-cell stage (Dziadek and Timpl, 1985). Laminin has diverse roles in development; for example, it is required for the proper development of many organs, including, muscle, heart, and kidney, as well as the nervous system, such as structuring the synapse (Noakes et al., 1995; Yarnitzky and Volk, 1995; Patton et al., 1998; Sanes et al., 1998; Allamand and Campbell, 2000; Miner and $\mathrm{Li}, 2000$ ). How can laminin be crucial for so many diverse developmental events? One way is through spatial and temporal regulation of expression of different isoforms of laminin, as observed in muscle (Miner et al., 1997; Patton et al., 1997). Another way is through expression of different receptors at the cell surface. Laminin has been shown to have many receptors, including several classes of integrins, the LAR family of receptor-tyrosine phosphatases, and $\alpha$-dystroglycan (Powell and Kleinman, 1997; O'Grady et al., 1998; Montanaro et al., 1999). Integrins have been found to mediate laminin-dependent neurite outgrowth (Tomaselli et al., 1990; for review, see Powell and Kleinman, 1997). To investigate potential receptors that may be mediating the effects of laminin at the growth cone, immunolocalization of integrin receptors was conducted. On whole embryos, polyclonal antisera generated from the entire $\beta 1$ subunit of integrin, as well as another antibody that recognizes the intracellular domain, stained epithelial cell boundaries (data not shown). Because this staining was quite intense, Ti1 neurons could not be visualized. Therefore, limbs were filleted open and immobilized on poly-Llysine-coated coverslips and double-labeled with HRP and $\beta 1$ integrin immunofluorescence (Fig. $3 A, B$ ) and polyclonal antibodies to the intracellular domain of $\beta 1$-integrin (Fig. $3 C, D$ ). In this preparation, $\beta 1$-integrin was found on Ti1 cell bodies, axons, and growth cones at $32-35 \%$ of development (Fig. $3 B, C$ ), during the time when Ti1 axons are navigating to the CNS. Ti1 neurons labeled with anti- $\beta 1$ antibodies alone showed the same pattern of labeling as neurons that were double-labeled with anti-HRP (Fig. 3, compare $A$ and $B$ with $C$ ). In addition to the neuronal labeling, integrin was expressed at epithelial cell boundaries as well as on mesodermal cells (Fig. $3 C, D$ ). Expression of $\beta 1$-integrin on Ti1 growth cones (Fig. $3 A, B$ ) suggests that integrins could be transducing laminin signals from the basal lamina.

\section{Blocking a conserved nidogen recognition sequence on laminin disrupts axon guidance}

Laminin is found along the entire course of Ti1 axon trajectory (Fig. 2), suggesting that laminin is conferring information to the Ti1 growth cones throughout their migration. Confocal analysis of laminin immunofluorescence in the developing limb bud basal lamina demonstrates that the distribution of laminin is uniform (Fig. $1 B$ ), suggesting that laminin may play a permissive role in axon guidance. EGF repeat-containing domain III of grasshopper laminin $\gamma$ contains a completely conserved nidogen-binding site (Gerl et al., 1991; Mayer et al., 1993a; Poschl et al., 1996; our unpublished results). Antibodies generated against this region have shown that this site is important for epithelial morphogenesis (Ekblom et al., 1994; Kadoya et al., 1997), and nidogen has
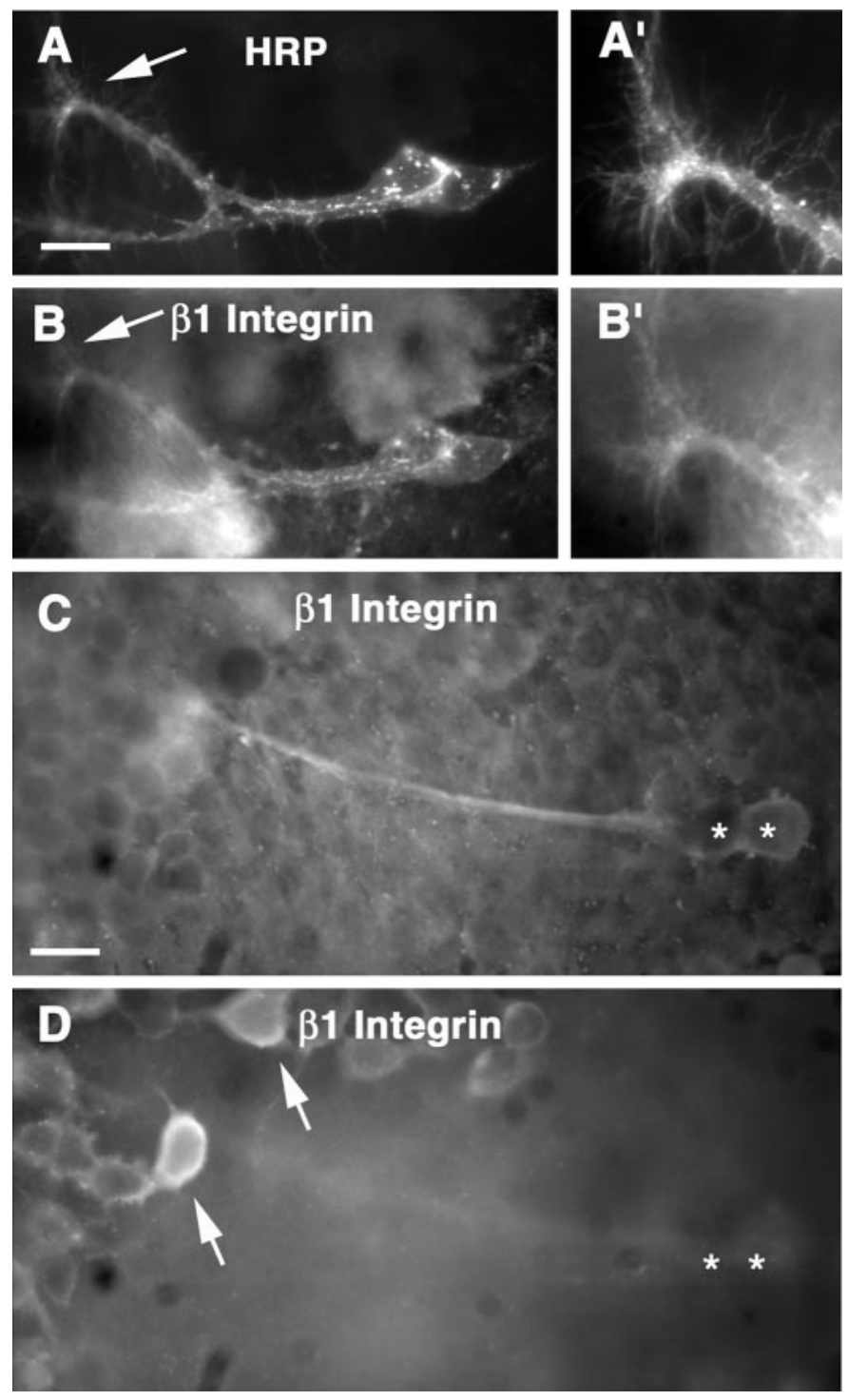

Figure 3. $\quad \beta 1$-Integrin is expressed in the developing limb bud. $A, B$, Ti1 neurons at $32 \%$ of development are labeled with anti-HRP antibodies $(A)$ and $\beta 1$-integrin $(B)$. The arrow indicates a growth cone that is depicted at higher magnification in $A^{\prime} . B, \beta 1$-Integrin immunofluorescence of the same neuron in $A$. $\beta 1$-Integrin localizes to the cell bodies, axons, and growth cones of the Ti1 neurons. $\beta 1$-Integrin is also expressed by epithelium and mesoderm, which accounts for the out-of-focus staining. The arrow in $B$ indicates the growth cone that is magnified in $B^{\prime} . B^{\prime}, \beta 1-$ Integrin is expressed on the growth cones of Til sensory axons. $C$, $\beta 1$-Integrin staining is confirmed with a different antibody. In an embryo at $34 \%$ of development labeled only with $\beta 1$-integrin antibodies, $\beta 1$ integrin is expressed in Ti1 cell bodies (asterisks) and axons. Growth cones are out of the field of view. Ti1 axons migrate along an epithelium that expresses $\beta 1$-integrin at cell junctions. $D$, Mesodermal cells, possibly hemocytes, express high levels of $\beta 1$-integrin. Shown is the same embryo depicted in $C$ but at a slightly different focal plane to emphasize mesodermal staining. Ti1 cell bodies (out of focus) are indicated by asterisks. Scale bars, $10 \mu \mathrm{m}$.

recently been shown to direct migrating neurons (Kim and Wadsworth, 2000). Previous studies have demonstrated that both antibodies and peptides directed at this site interfere with nidogen binding to laminin (Mayer et al., 1993a). With this in mind, antibodies and peptides were designed to target this site, to disrupt laminin-nidogen interactions, and to determine their role in axon guidance. Grasshopper embryos were cultured in the 
Figure 4. Disruption of laminin-nidogen interactions results in aberrant neuronal pathfinding. $A$, Control culture demonstrating the Ti1 pathway as visualized with HRP immunofluorescence. Culturing in preimmune sera $(P I)$ or randomly scrambled peptides (see Results) has no effect on Ti1 pathfinding. $B$, Stalled Ti1 axons when laminin-nidogen is blocked. Ti1 neurons have brightly labeled cell bodies, axons, and extended growth cones, indicative of healthy neurons. $C$, Embryo after culturing with laminin $\gamma$ antisera with the addition of anti-rabbit secondary antibody demonstrating that the antiserum has penetrated the limb bud and is localized, binding to laminin epitopes found in the basal lamina and on hemocytes. Antibodies have access to the lumen of the limb bud during the culture period. $D$, Antibodies and peptides to the nidogen-binding site on laminin disrupts neuronal pathfinding. In $24 \mathrm{hr}$ cultures, both antibodies to the nidogen-binding site (Gamma $A b)$ and peptides $(D P N A V)$ result in an increase in total Ti1 pathfinding errors ( first
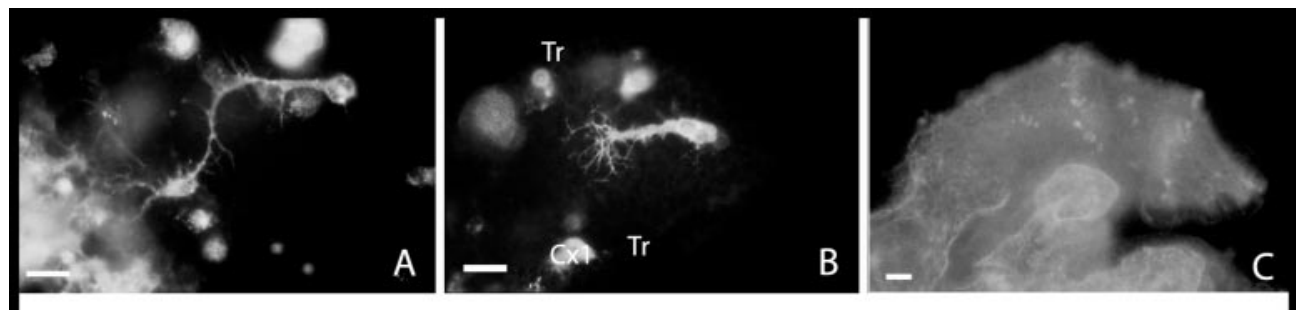

Gamma Chain (24 hours)

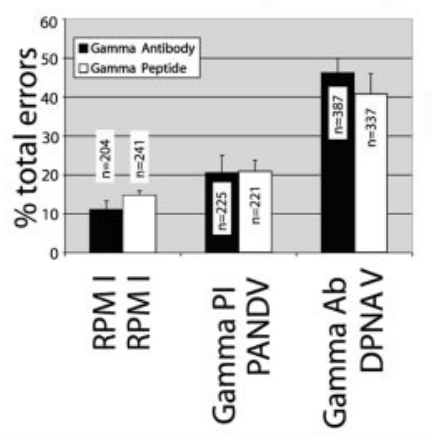

Distribution of Errors

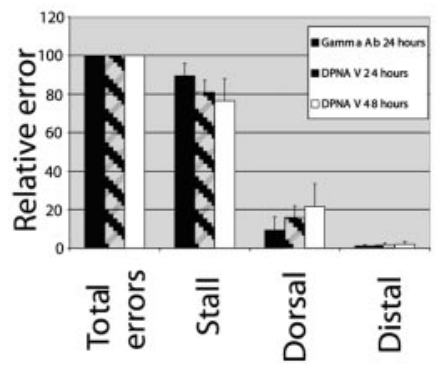

D

graph). The total Ti1 pathfinding error was normalized to $100 \%$, and the total errors were broken down into categories (see Results). In both 24 and $48 \mathrm{hr}$ cultures, most errors were stalled axons (second graph). Scale bars: $A, B, 20 \mu \mathrm{m} ; C, 30 \mu \mathrm{m}$.

presence of these reagents at $30 \%$ of embryonic development, and the effect of Ti1 pathfinding was studied.

Embryos at $30 \%$ of development were cultured for $24 \mathrm{hr}$ at $30^{\circ} \mathrm{C}$ in the presence of $1 \mu \mathrm{M}$ anti- $\gamma \mathrm{IgG}$ antibodies and the synthetic peptide DPNAV $(0.2 \mathrm{mg} / \mathrm{ml})$. As controls, IgG-isolated preimmune sera and the randomly scrambled peptide PANDV at the same concentrations as $\gamma$ antisera and DPNAV, respectively, were used. Ti1 neurons exhibited three types of pathfinding errors. The most prominent error, stalled axons, is characterized by the failure of both Ti1 growth cones to initiate the ventral turn at the trochanter segment and to extend to the CNS (Fig. 4, compare $A$ and $B$ ). One or both of the Ti1 axons extending in the dorsal epithelium of the limb compartment typify the second type of abnormality, a dorsal projection. Finally, the third abnormality is characterized by a distal projection of one or both Ti1 axons from the cell bodies instead of extending proximally. However, a small number of dorsal and distal errors were also found in control embryos. A comparison of the dorsal and distal error rate in control cultures with experimental cultures revealed that there was no statistical difference between control and treated embryos. Importantly, for both blocking reagents, similar abnormalities were observed, suggesting that both reagents were acting by the same mechanism, probably as competitive inhibitors.

The rate of disrupted Ti1 pathways when cultured with $1 \mu \mathrm{M} \gamma$ antibody was significantly higher than controls, at rates of $46 \pm$ $3.7 \%(n=387$, six independent trials; Fig. $4 D)$, compared with $11.1 \pm 2.2 \%$ in RPMI medium and $20.6 \pm 4.5 \%$ with preimmune sera; $p=5.2 \times 10^{-6}$ for RPMI versus $\gamma$ antibody; $p=0.0007$ for preimmune versus $\gamma$ antibody (unpaired Student's $t$ test). Similarly, $41 \pm 5.2 \%$ of embryos that were cultured in the presence of $0.2 \mathrm{mg} / \mathrm{ml}$ DPNAV $(n=337$, six independent trials; Fig. $4 D)$ exhibited disrupted Ti1 pathways compared with $14.8 \pm 1.1 \%$ for RPMI medium and $21 \pm 2.8 \%$ for control peptide; $p=0.00031$ for RPMI versus DPNAV; $p=0.004$ for control peptide versus DPNAV. The most frequent error in the Ti1 pathway after laminin-nidogen block was stalled axons, (Fig. 4, compare $A$ and $B)$. The integrity of the growth cones and the Ti1 cell bodies suggested that cell death was not a factor in these experiments (Fig. 4B). In antibody- and peptide-blocked embryos, $89 \pm 6.4 \%$ $(n=181)$ and $80 \pm 6.2 \%(n=131)$ of total errors were of the stalled variety (Fig. $4 D$ ). The other errors were dorsal projections (at rates of $9.4 \pm 6.7$ and $16 \pm 5.9 \%$ for antibody and peptide, respectively) and distal projections (at rates of $1.1 \pm 0.67$ and $1.5 \pm 1.3 \%$ for antibody and peptide, respectively).

A salient feature of the stalled axons is the location within the Ti1 pathway in which Ti1 axons stall. Stalled Ti1 axons were never observed proximal to the ventral turn, for example, never after committing to the ventral turn, or in the vicinity of the $\mathrm{Cx} 1$ cells (Fig. 4B). Therefore, it appeared that Ti1 axons either stalled before the ventral turn or completed the pathway. Several mechanisms could account for the cessation of growth and the inability of Ti1 axons to complete their trajectory. One explanation is the possibility that these neurons are growing slower than in control cultures. Previous work has shown that the growth rate of neurons in vitro is substrate-dependent. For example, chick dorsal root ganglion neurons extend two times faster on laminin than on fibronectin (Kuhn et al., 1995). Because Ti1 growth cones intimately associate with the basal lamina in the developing limb bud (Anderson and Tucker, 1988), it is possible that Ti1 growth cones exhibit substantially retarded growth as a result of the disruption of laminin-nidogen interactions. This would also account for the consistency of the location of the stall, because embryos are cultured for 22-24 hr.

To address whether Ti1 axons exhibit slower growth rates when laminin-nidogen is blocked, two sets of experiments were conducted. First, the growth rate of laminin-blocked Ti1 axons was examined as they extended toward the trochanter. Embryos were cultured in the presence of blocking peptides at $31 \%$ of development for $12 \mathrm{hr}$, and axons were scored according to their location in the limb bud. In embryos cultured for $12 \mathrm{hr}$ in the presence of $0.2 \mathrm{mg} / \mathrm{ml}$ DPNAV, $13.6 \pm 7.1 \%(n=118)$ of growing axons reached the femur limb segment, compared with $19.8 \pm 1 \%(n=$ $81)$ and $9.7 \pm 5.1 \%(n=74)$ for PANDV and RPMI, respectively (Fig. $5 A$ ); $39.1 \pm 4.2 \%$ of DPNAV-blocked axons reached the 


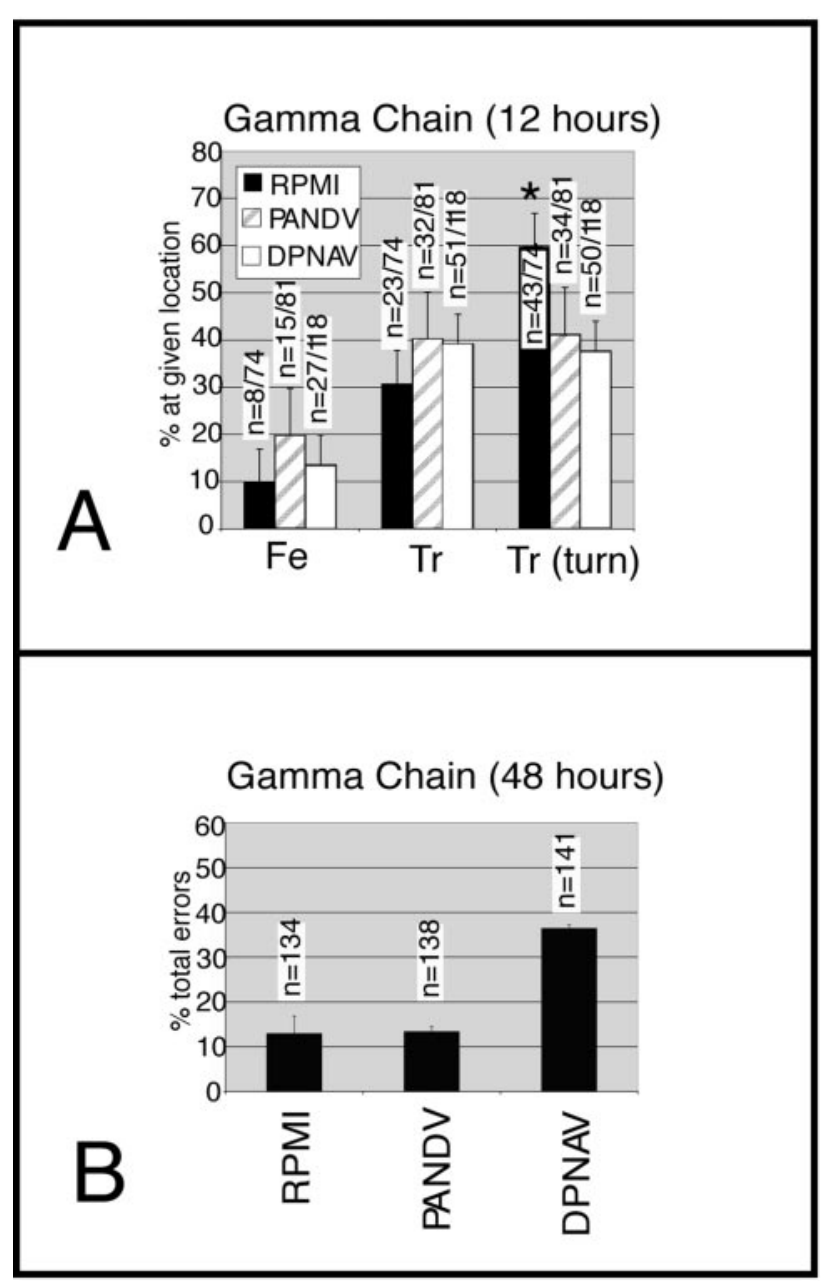

Figure 5. Growth rate of Ti1 axons is unaffected in laminin-nidogenblocked embryos. $A$, The growth rate of Ti1 axons before the trochanter was determined by culturing embryos for a shortened period of $12 \mathrm{hr}$ and the location of growth cones was determined. At the femur $(\mathrm{Fe})$ and trochanter $(T r)$ there is no difference between laminin-nidogen-blocked embryos (DPNAV) compared with peptide control (PANDV) and RPMI medium. However, a significantly higher number of control growth cones are found after the ventral turn in the trochanter [ $\operatorname{Tr}$ (turn)] compared with control peptide and laminin-nidogen-blocked embryos. $B$, Growth rate of Ti1 axons after the trochanter was assessed by extending the culture period to $48 \mathrm{hr}$. After $48 \mathrm{hr}$, the Ti1 axons exhibit the same frequency of pathfinding errors, similar to $24 \mathrm{hr}$ cultures (compare with Fig. $4 D)$.

trochanter (but did not turn), compared with $40.2 \pm 9.5 \%$ and $30.6 \pm 3.4$ in PANDV and RPMI medium, respectively (Fig. $5 A$ ). Importantly, there was no significant difference between controls and DPNAV-blocked embryos in these regions of the limb (Fig. $5 A$ ), indicating that laminin-nidogen-blocked axons reach the trochanter at the same time as control cultures and have access to the same developmental cues. However, when axons were examined after the ventral turn [Fig. $5 A, \operatorname{Tr}$ (turn)], there was a slight, significant increase in numbers of axons that had turned in control versus peptide-blocked cultures ( $p=0.04$ for RPMI vs DPNAV), which is consistent with the stall phenotype.

To address whether Ti1 axons required additional time to make the ventral turn and grow down the trochanter, embryos were cultured in the presence of DPNAV blocking peptide for an additional $24 \mathrm{hr}$ (total culture time, $48 \mathrm{hr}$ ). When cultured for 48 $\mathrm{hr}$, a similar number of aberrant projections were observed; $36 \pm$
$0.75 \%$ of axons were abnormal $(n=141 ; p=0.0021$ for RPMI vs DPNAV peptide; $p=3.6 \times 10^{-5}$ for control peptide vs DPNAV; Fig. $5 B$ ). The distribution of errors was not significantly different: $76.5 \pm 11.4 \%$ stalled; $21.6 \pm 11.7 \%$ extended aberrantly dorsally; and $2 \pm 1.4 \%$ grew distally $(n=51$; Fig. $4 D)$. Therefore, despite the extended culture period, the Ti1 growth cones ceased growth at the same location within the limb at the trochanter limb segment epithelium. These results suggest that the stalled phenotype is not attributable to a slower rate of growth along the limb epithelium but is attributable to an inability to turn at the trochanter.

\section{Ti1 axons stall within the filopodial range of guidance cues found within the trochanter}

The proximal extension of Ti1 axons is followed by a ventral turn in the trochanter limb segment. The trochanter epithelium contains pertinent guidance information that may be important for directing a correct ventral turn, for example, members of the semaphorin family (Isbister et al., 1999). Although semaphorin 1a is expressed in a circumferential band of epithelium in the trochanter limb segment, semaphorin 2a exhibits a dorsal-to-ventral graded distribution in this region (Kolodkin et al., 1992; Isbister et al., 1999). If Ti1 axons stall before the trochanter epithelium, then they may not be within filopodial range of important guidance information. If the growth cones stall within the trochanter, this would suggest that Ti1 growth cones have access to semaphorins but may not be able to respond to them. To establish whether Ti1 axons are within the range of cues found in the trochanter, the location of stalled axons was assessed using two criteria. First, semaphorin 1a immunofluorescence was used as a marker of the trochanter limb segment. Second, the location of stalled Ti1 axons in relation to a pair of preaxonogenesis neurons, the $\mathrm{Cx} 1$ cells, was used. These cells lie just proximal to the trochanter limb segment in the distal compartment of the coxa segment (Fig. 6A). The neuronal marker used in all blocking experiments, anti-HRP, also labels these preaxonogenesis neurons. Embryos were cultured overnight in the presence of DPNAV blocking peptide, fixed, and stained for both HRP and semaphorin 1a immunoreactivity. Stalled Ti1 axons were scored in relation to semaphorin 1a-expressing epithelium (Kolodkin et al., 1992) or in relation to the Cx1 cells (Fig. 6A). Ti1 axons were scored as stalling before the trochanter (Fig. 6A), within the trochanter (Fig. $6 B$ ), or after the trochanter but not turning (Fig. $6 C)$. Using these criteria, $73 \%$ of stalled Ti1 growth cones resided within the trochanter (Fig. 6D), whereas 17 and $8.7 \%$ stalled before and after the trochanter, respectively $(n=23$; Fig. $6 E)$. Interestingly, the small number of axons that were found after the trochanter had not initiated a ventral turn; instead they had continued extending proximally. These results would suggest that the majority of stalled Ti1 growth cones $(81.7 \%$, those that stalled in the trochanter and those that stalled past the trochanter) had access to guidance information within the trochanter, such as semaphorins, but were unable to respond to it.

\section{Basal lamina integrity}

The complex arrangement of the basal lamina results from selfassembly of laminin and type IV collagen as well as from interactions between these networks and other basal lamina constituents (Yurchenco and Furthmayr, 1984; Yurchenco et al., 1985; Timpl and Brown, 1996; Cheng et al., 1997). Genetic knock-out of basal lamina molecules often results in a disrupted basal lamina, for example, in the case of laminin, type IV collagen, and perle- 
Figure 6. Ti1 axons stall in a discrete location in the limb bud when laminin-nidogen is blocked. $A-C$, Schematic depicting the three possible locations of stalled Ti1 axons, as assessed with HRP and semaphorin immunofluorescence. $D$, Laminin-and nidogen-blocked embryo that has been labeled with HRP to visualize neurons; arrowheads indicate trochanter. $E$, The location of 23 stalled Ti1 growth cones was determined; $73 \%$ of stalled Ti1 axons resided within the trochanter $(T r)$, site of the ventral turn. Scale bar, $30 \mu \mathrm{m}$.

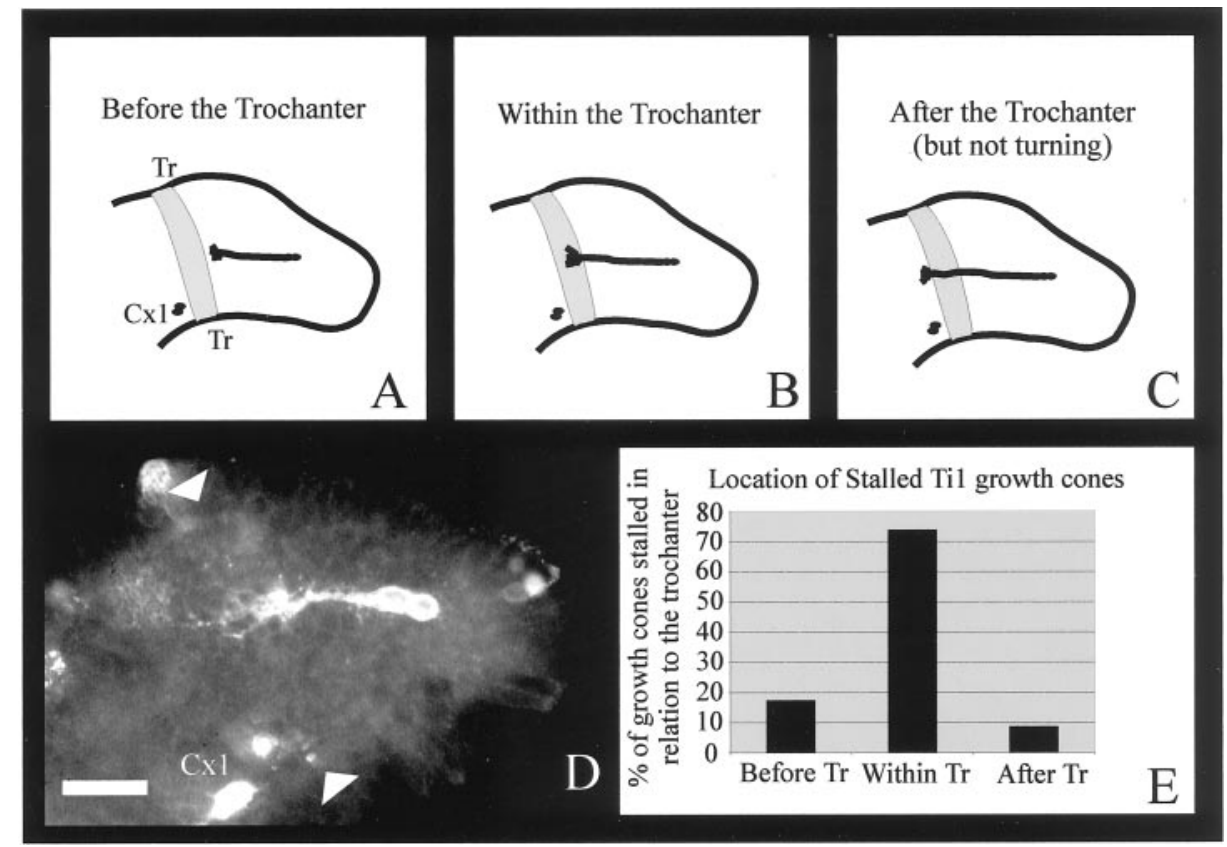

can but not in the case of nidogen (Garcia-Alonso et al., 1996; Costell et al., 1999; Kim and Wadsworth, 2000; Miner and Li, 2000; Murshed et al., 2000; Norman and Moerman, 2000). Although genetic disruption of nidogen does not affect basal lamina integrity, antibodies to the nidogen binding site on laminin disrupt the basal lamina in vitro (Kadoya et al., 1997). Therefore, interference of laminin-nidogen interactions with antibodies and peptides could result in a disruption of the basal lamina. Additionally, basal lamina disruptions could alter the localization of secreted guidance molecules. For example, secreted members of the semaphorin family may require laminin or another component of the basal lamina for proper localization.

To assess whether neurons ceased growth because of an alteration of the basal lamina or distribution of secreted semaphorins, laminin and semaphorin $2 \mathrm{a}$ distributions were examined in embryos cultured in the presence of blocking peptide. If the basal lamina had suffered a structural defect, then laminin immunoreactivity may appear disrupted. In laminin-nidogen peptideblocked embryos, immunofluorescence of laminin was similar to that of control embryos (Fig. 7A,B). Laminin protein was evenly distributed similar to control cultures, indicating that the laminin network was not severely disrupted. Figure $7 B$ depicts stalled Ti1 growth cones in the trochanter, surrounded by a normal laminin distribution. To determine whether secreted guidance molecules are disrupted in blocked embryos, semaphorin 2a immunofluorescence was used. Semaphorin $2 \mathrm{a}$ is secreted and is normally localized in a dorsal-to-ventral and distal-to-proximal gradient (Fig. 7C; Isbister et al., 1999; Bonner and O'Connor, 2000). In peptide-blocked embryos, semaphorin 2 a distribution is similar to that of control cultures, suggesting that at least in the case of semaphorin 2a, secreted guidance cue localization was intact. Stalled Ti1 axons therefore have access to appropriately localized semaphorin 2a (Fig. 7D, arrow), which repels Ti1 axons from the dorsal limb compartment. Furthermore, from these experiments, it appears that the extracellular graded distribution of semaphorin 2 a does not require laminin-nidogen interactions.

\section{DISCUSSION}

During the establishment of the Ti1 pathway, laminin immunoreactivity is evenly distributed in the basal lamina. This suggests that laminin is a permissive cue for migrating Ti1 axons. $\beta 1$ integrin was found on the cell bodies, axons, and importantly, on the growth cones of Ti1 neurons, implicating these receptors as potential mediators of laminin signals. Disruption of the lamininnidogen interaction during development of the Ti1 pathway disrupts pioneer neuron pathfinding. Typically, the Ti1 growth cones cease proximal extension and cannot navigate an essential ventral turn, resulting in stalled axons. This does not appear to be attributable to a slower growth rate, because blocked Ti1 axons arrive at the trochanter at the same time. In addition, extending the length of the culture period does not overcome the effect of peptides and antibodies. Localization of stalled growth cones indicates that they stall within a region of semaphorin expression in the trochanter limb segment, and in the case of secreted semaphorins, these cues are properly localized. In addition, the basal lamina is not disrupted in antibody- and peptide-blocked embryos.

\section{The basal lamina is intact in laminin-nidogen-blocked embryos}

Because the antibodies and peptides used in this study were designed to disrupt basal lamina interactions, and were found to disrupt the integrity of the basal lamina in vitro (Kadoya et al., 1997) it was essential to determine the structural integrity of the basal lamina in laminin- and nidogen-blocked embryos. We demonstrated that laminin and semaphorin 2 a distribution was unaffected in laminin- and nidogen-blocked embryos at the light microscopic level. Thus from these observations we conclude that blocking laminin and nidogen using antibodies and peptides causes a discrete and specific molecular lesion that does not compromise the integrity of the basal lamina or the localization of other secreted molecules. Furthermore, blocking a cell adhesion site on the $\beta$-chain of laminin that is involved in modulating netrin activity (Hopker et al., 1999) has no effect on Ti1 path- 

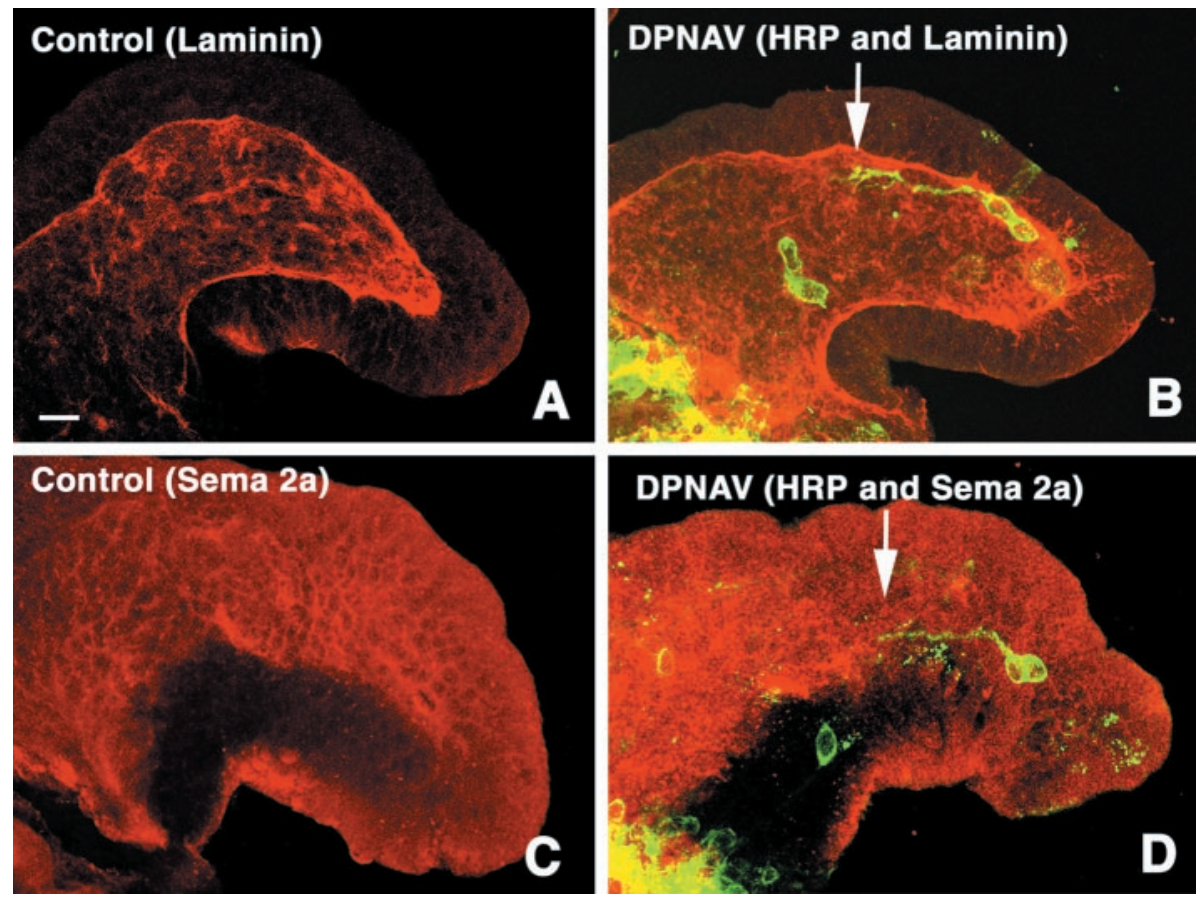

Figure 7. Basal lamina and secreted guidance cue localization are intact in laminin- and nidogen-blocked embryos. $A$, Immunofluorescence microscopy of a control embryo that has been double-labeled with laminin antisera (red) and HRP (green). B, DPNAV-blocked embryo that has been double-labeled with laminin (red) and HRP (green). Ti1 axons stall in the trochanter (arrow), and basal lamina integrity is normal. $C$, Semaphorin 2a (Sema 2a), a secreted guidance cue, is distributed in a dorsal-to-ventral and distal-to-proximal gradient (Isbister et al., 1999) in control cultures. $D$, Semaphorin 2a distribution is preserved in DPNAV-blocked embryos. In this embryo, Ti1 axons (green) have stalled in the trochanter (arrow), and semaphorin 2a (red) is expressed in a dorsal-to-ventral and distal-toproximal gradient. Scale bar, $20 \mu \mathrm{m}$. finding (data not shown). Therefore, the defects observed with laminin and nidogen blocking are a direct result of blocking this site and not a general effect of blocking laminin or a secondary effect of disrupting basal lamina interactions.

\section{Role of basal lamina in neuronal pathfinding}

We have shown a surprising role of laminin in neuronal pathfinding. Previous work by Condic and Bentley (1989a) suggests an adhesive role for the basal lamina, because they found that enzymatic removal of the basal lamina resulted in decreased neuronal adhesion to the substratum and axon retraction to the cell bodies. Surprisingly, Ti1 axons could extend and pathfind in the absence of a basal lamina (Condic and Bentley, 1989c). One possible explanation for this is that enzymatic removal of the basal lamina may result in a compensatory mechanism within Ti1 growth cones, such that they no longer depend on the basal lamina for adhesive contacts. Consistent with this idea, they found that in the absence of the basal lamina, Ti1 axons could adhere to the epithelium in regions where they normally relied on basal lamina adhesion as well (Condic and Bentley, 1989c). This indicates that the neurons are capable of compensating for the lack of basal lamina interactions, perhaps by downregulating basal lamina receptors such as integrins and upregulating cell adhesion molecules. It is possible that in our study, disrupting the laminin-nidogen interactions may be insufficient to effect the expression of cell adhesion molecules of the Ti1 growth cones. Therefore, if a compensatory mechanism within Ti1 growth cones accounts for proper pathfinding in the absence of basal lamina, as in the studies of Condic and Bentley (1989a,c), this mechanism may not have been activated in laminin- and nidogen-blocked embryos.

\section{Growth cone responsiveness may underlie permissive cue signaling}

The pathfinding of neuronal growth cones relies on several factors, which can be classified as instructive or permissive. A balance of growth cone adhesion to the substratum and growth cone motility is essential to guarantee growth cone responsiveness. If this balance is disrupted, the growth cone may not be able to respond to instructive cues, resulting in pathfinding errors. Hopker et al. (1999) have demonstrated that laminin can alter the guidance activity of the laminin-related netrin family of molecules, suggesting that the simultaneous presentation of instructive and permissive cues is pertinent to the effect of guidance molecules. In the developing limb bud, laminin has the potential to modulate the activity of several guidance molecules because of its ubiquitous and even distribution in the basal lamina during axon outgrowth. In this capacity, laminin could be an important cofactor to guidance molecules that guide Ti1 neurons.

Because the growth cone is in constant contact with the environment, sampling and responding to many molecular cues, disruption of laminin-nidogen interactions in the immediate environment of the Ti1 growth cones could have severe effects on the molecular constituents found on the growth cone. It has recently been demonstrated that integrin levels in neuronal growth cones can be rapidly modulated based on availability of both laminin and aggrecan in vitro (Condic and Letourneau, 1997; Condic et al., 1999), implicating integrins as mediators of the balance between adhesion to the substratum and growth cone motility. Condic and Letourneau (1997) have established that when neurons are plated on low laminin concentrations, integrin receptors increase on the growth cones, resulting in increased adhesion to various substrates, suggesting that neurons can rapidly and dynamically respond to their environment and can maintain a balance between adhesion and motility. When applied to our system, blocking laminin in the developing embryo could increase integrin receptors on the growth cone, thereby increasing adhesion to the substratum, resulting in decreased motility at the trochanter.

Why is motility inhibited at the ventral turn and not before? One possibility is that a combination of permissive and instructive cues is important for generating the abrupt turn that growth cones make in the trochanter. For example, although an instructive guidance cue may be signaling the growth cone with respect to the directionality of a turn, a concomitant permissive signal 
may also be required. This scenario would suggest that the pathfinding in the femur does not require laminin signaling. In this region, the graded expression of semaphorin $2 \mathrm{a}$ may be sufficient for guiding Ti1 axons proximally (Isbister et al., 1999). In contrast, possibly a number of cues, including laminin, are required to generate the abrupt ventral turn in the trochanter.

Although Ti1 axons may be incapable of turning, why do the growth cones stall in the trochanter and not continue proximal growth? Previous work has demonstrated that the trochanter epithelium is substantially more adhesive for Ti1 growth cones than epithelium in other areas of the limb bud (Condic and Bentley, 1989b; Isbister and O'Connor, 1999). The simplest explanation is that in the absence of a turning signal, the Ti1 growth cones prefer to remain on the highly adhesive trochanter rather that extend proximally into the coxa. This could be mediated in part by upregulation of receptors on the growth cones, which could increase growth cone adhesion.

\section{Potential roles of nidogen}

When the nidogen-binding site on laminin is blocked, Ti1 axons stall at the location of a stereotyped ventral turn. Because laminin is evenly expressed in this region, it is not likely that laminin is a chemoattractant that directs axons ventrally, nor is it likely to be a chemorepulsive agent that repels axons from the dorsal epithelium. Therefore, why do disruptions in laminin-nidogen interactions perturb axon pathfinding? One explanation is that the defects observed could be attributable to disruption of nidogen function rather than laminin function. Once nidogen is removed from the laminin heterotrimer, it is susceptible to degradation by proteases (Mayer et al., 1993b), however, it is unclear whether this is the case in laminin-nidogen-blocked embryos. The expression pattern of nidogen in the developing embryo is unknown, and the possibility that nidogen is discretely expressed in the developing limb bud cannot be discounted. As a result, discrete localization of nidogen could guide Ti1 neurons directly. Alternatively, nidogen could act in concert with other guidance cues to facilitate the steering event. Kim and Wadsworth (2000) have demonstrated that nidogen is essential for pathfinding of neurons in Caenorhabditis elegans and may modulate the effect of other guidance cues such as netrins. Thus nidogen has important guidance activity and could be the sole mediator of the stalled Ti1 axon effect.

As they migrate, growth cones encounter different cues that are spatially and temporally regulated. The exact sequence of encountered cues may be critical for the growth cone to appropriately respond to future guidance information, suggesting that the growth cone retains information, perhaps in the form of modulated receptor subtypes (Dodd et al., 1988; Shirasaki et al., 1998; Brose and Tessier-Lavigne, 2000; Diefenbach et al., 2000). Because the ventral turn of the Ti1 neurons involves multiple cues, we speculate that permissive cues are responsible for guaranteeing that the growth cone expresses the appropriate complement of receptors for permissive cues, such as integrins, to facilitate axon pathfinding.

\section{REFERENCES}

Allamand V, Campbell KP (2000) Animal models for muscular dystrophy: valuable tools for the development of therapies. Hum Mol Genet 9:2459-2467.

Anderson H, Tucker RP (1988) Pioneer neurones use basal lamina as a substratum for outgrowth in the embryonic grasshopper limb. Development 104:601-608.

Anderson H, Tucker RP (1989) Spatial and temporal variation in the structure of the basal lamina in embryonic grasshopper limbs during pioneer neurone outgrowth. Development 106:185-194.

Bentley D, Keshishian H, Shankland M, Toroian-Raymond A (1979) Quantitative staging of embryonic development of the grasshopper, Schistocerca nitens. J Embryol Exp Morphol 54:47-74.

Bonner J, O'Connor TP (2000) Semaphorin function in the developing invertebrate peripheral nervous system. Biochem Cell Biol 78:603-611.

Brose K, Tessier-Lavigne M (2000) Slit proteins: key regulators of axon guidance, axonal branching, and cell migration. Curr Opin Neurobiol 10:95-102.

Calof AL, Campanero MR, O'Rear JJ, Yurchenco PD, Lander AD (1994) Domain-specific activation of neuronal migration and neurite outgrowth-promoting activities of laminin. Neuron 13:117-130.

Cheng YS, Champliaud MF, Burgeson RE, Marinkovich MP, Yurchenco PD (1997) Self-assembly of laminin isoforms. J Biol Chem 272:31525-31532.

Cohen J, Burne JF, Winter J, Bartlett P (1986) Retinal ganglion cells lose response to laminin with maturation. Nature 322:465-467.

Cohen J, Nurcombe V, Jeffrey P, Edgar D (1989) Developmental loss of functional laminin receptors on retinal ganglion cells is regulated by their target tissue, the optic tectum. Development 107:381-387.

Condic ML, Bentley D (1989a) Removal of the basal lamina in vivo reveals growth cone-basal lamina adhesive interactions and axonal tension in grasshopper embryos. J Neurosci 9:2678-2686.

Condic ML, Bentley D (1989b) Pioneer growth cone adhesion in vivo to boundary cells and neurons after enzymatic removal of basal lamina in grasshopper embryos. J Neurosci 9:2687-2696.

Condic ML, Bentley D (1989c) Pioneer neuron pathfinding from normal and ectopic locations in vivo after removal of the basal lamina. Neuron 3:427-439.

Condic ML, Letourneau PC (1997) Ligand-induced changes in integrin expression regulate neuronal adhesion and neurite outgrowth. Nature 389:852-856.

Condic ML, Snow DM, Letourneau PC (1999) Embryonic neurons adapt to the inhibitory proteoglycan aggrecan by increasing integrin expression. J Neurosci 19:10036-10043.

Costell M, Gustafsson E, Aszodi A, Morgelin M, Bloch W, Hunziker E, Addicks K, Timpl R, Fassler R (1999) Perlecan maintains the integrity of cartilage and some basement membranes. J Cell Biol 147:1109-1122.

Diefenbach TJ, Guthrie PB, Kater SB (2000) Stimulus history alters behavioral responses of neuronal growth cones. J Neurosci 20:1484-1494.

Dodd J, Morton SB, Karagogeos D, Yamamoto M, Jessell TM (1988) Spatial regulation of axonal glycoprotein expression on subsets of embryonic spinal neurons. Neuron 1:105-116.

Dziadek M, Timpl R (1985) Expression of nidogen and laminin in basement membranes during mouse embryogenesis and in teratocarcinoma cells. Dev Biol 111:372-382.

Ekblom P, Ekblom M, Fecker L, Klein G, Zhang HY, Kadoya Y, Chu ML, Mayer U, Timpl R (1994) Role of mesenchymal nidogen for epithelial morphogenesis in vitro. Development 120:2003-2014.

Forrester WC, Garriga G (1997) Genes necessary for C. elegans cell and growth cone migrations. Development 124:1831-1843.

Garcia-Alonso L, Fetter RD, Goodman CS (1996) Genetic analysis of laminin A in Drosophila: extracellular matrix containing laminin A is required for ocellar axon pathfinding. Development 122:2611-2621.

Gerl M, Mann K, Aumailley M, Timpl R (1991) Localization of a major nidogen-binding site to domain III of laminin B2 chain. Eur J Biochem 202:167-174.

Halfter W (1996) The behavior of optic axons on substrate gradients of retinal basal lamina proteins and merosin. J Neurosci 16:4389-4401.

Hall DE, Neugebauer KM, Reichardt LF (1987) Embryonic neural retinal cell response to extracellular matrix proteins: developmental changes and effects of the cell substratum attachment antibody (CSAT). J Cell Biol 104:623-634.

Harlow E, Lane DP (1988) Antibodies, a laboratory manual. New York: Cold Spring Harbor Laboratory.

Hopker VH, Shewan D, Tessier-Lavigne M, Poo M, Holt C (1999) Growth-cone attraction to netrin-1 is converted to repulsion by laminin-1. Nature 401:69-73.

Isbister CM, O'Connor TP (1999) Filopodial adhesion does not predict growth cone steering events in vivo. J Neurosci 19:2589-2600.

Isbister CM, Tsai A, Wong ST, Kolodkin AL, O'Connor TP (1999) Discrete roles for secreted and transmembrane semaphorins in neuronal growth cone guidance in vivo. Development 126:2007-2019.

Ivins JK, Colognato H, Kreidberg JA, Yurchenco PD, Lander AD (1998) Neuronal receptors mediating responses to antibody-activated laminin-1. J Neurosci 18:9703-9715.

Ivins JK, Yurchenco PD, Lander AD (2000) Regulation of neurite outgrowth by integrin activation. J Neurosci 20:6551-6560.

Kadoya Y, Salmivirta K, Talts JF, Kadoya K, Mayer U, Timpl R, Ekblom $P$ (1997) Importance of nidogen binding to laminin gamma1 for branching epithelial morphogenesis of the submandibular gland. Development 124:683-691. 
Keshishian H, Bentley D (1983) Embryogenesis of peripheral nerve pathways in grasshopper legs: I. The initial nerve pathway to the CNS. Dev Biol 96:89-102

Kim S, Wadsworth WG (2000) Positioning of longitudinal nerves in $C$. elegans by nidogen. Science 288:150-154.

Kolodkin AL, Matthes DJ, O'Connor TP, Patel NH, Admon A, Bentley D, Goodman CS (1992) Fasciclin IV: sequence, expression, and function during growth cone guidance in the grasshopper embryo. Neuron 9:831-845

Kuhn TB, Schmidt MF, Kater SB (1995) Laminin and fibronectin guideposts signal sustained but opposite effects to passing growth cones. Neuron 14:275-285

Kuhn TB, Williams CV, Dou P, Kater SB (1998) Laminin directs growth cone navigation via two temporally and functionally distinct calcium signals. J Neurosci 18:184-194.

Matise MP, Lustig M, Sakurai T, Grumet M, Joyner AL (1999) Ventral midline cells are required for the local control of commissural axon guidance in the mouse spinal cord. Development 126:3649-3659.

Mayer U, Nischt R, Poschl E, Mann K, Fukuda K, Gerl M, Yamada Y, Timpl R (1993a) A single EGF-like motif of laminin is responsible for high affinity nidogen binding EMBO J 12:1879-1885.

Mayer U, Mann K, Timpl R, Murphy G (1993b) Sites of nidogen cleavage by proteases involved in tissue homeostasis and remodelling. Eur J Biochem 217:877-884.

Miner JH, Li C (2000) Defective glomerulogenesis in the absence of laminin alpha5 demonstrates a developmental role for the kidney glomerular basement membrane. Dev Biol 217:278-289.

Miner JH, Patton BL, Lentz SI, Gilbert DJ, Snider WD, Jenkins NA, Copeland NG, Sanes JR (1997) The laminin alpha chains: expression, developmental transitions, and chromosomal locations of alpha1-5, identification of heterotrimeric laminins $8-11$, and cloning of a novel alpha3 isoform. J Cell Biol 137:685-701.

Montanaro F, Lindenbaum M, Carbonetto S (1999) Alpha-dystroglycan is a laminin receptor involved in extracellular matrix assembly on myotubes and muscle cell viability. J Cell Biol 145:1325-1340.

Murshed M, Smyth N, Miosge N, Karolat J, Krieg T, Paulsson M, Nischt $\mathrm{R}$ (2000) The absence of nidogen 1 does not affect murine basement membrane formation. Mol Cell Biol 20:7007-7012.

Noakes PG, Gautam M, Mudd J, Sanes JR, Merlie JP (1995) Aberrant differentiation of neuromuscular junctions in mice lacking S-Laminin/ Laminin B2. Nature 374:258-262.

Norman KR, Moerman DG (2000) The let-268 locus of Caenorhabditis elegans encodes a procollagen lysyl hydroxylase that is essential for type IV collagen secretion. Dev Biol 227:690-705.

O'Grady P, Thai TC, Saito H (1998) The laminin-nidogen complex is a ligand for a specific splice isoform of the transmembrane protein tyrosine phosphatase LAR. J Cell Biol 141:1675-1684.

O'Connor TP (1999) Intermediate targets and segmental pathfinding. Cell Mol Life Sci 55:1358-1364.

O'Connor TP, Duerr JS, Bentley D (1990) Pioneer growth cone steering decisions mediated by single filopodial contacts in situ. J Neurosci 10:3935-3946.

Patton BL, Miner JH, Chiu AY, Sanes JR (1997) Distribution and function of laminins in the neuromuscular system of developing, adult, and mutant mice. J Cell Biol 139:1507-1521.

Patton BL, Chiu AY, Sanes JR (1998) Synaptic laminin prevents glial entry into the synaptic cleft. Nature 393:698-701.

Powell SK, Kleinman HK (1997) Neuronal laminins and their cellular receptors. Int J Biochem Cell Biol 29:401-414.

Poschl E, Mayer U, Stetefeld J, Baumgartner R, Holak TA, Huber R, Timpl R (1996) Site-directed mutagenesis and structural interpretation of the nidogen binding site of the laminin gamma1 chain. EMBO J 15:5154-5159.

Sanes JR, Apel ED, Burgess RW, Emerson RB, Feng G, Gautam M, Glass D, Grady RM, Krejci E, Lichtman JW, Lu JT, Massoulie J, Miner JH, Moscoso LM, Nguyen Q, Nichol M, Noakes PG, Patton BL, Son YJ, Yancopoulos GD, et al (1998) Development of the neuromuscular junction: genetic analysis in mice. J Physiol (Paris) 92:167-172.

Shirasaki R, Katsumata R, Murakami F (1998) Change in chemoattractant responsiveness of developing axons at an intermediate target. Science 279:105-107.

Smith DB, Johnson KS (1988) Single-step purification of polypeptides expressed in Escherichia coli as fusions with glutathione $S$-transferase. Gene 67:31-40.

Timpl R, Brown JC (1996) Supramolecular assembly of basement membranes. BioEssays 18:123-132.

Tomaselli KJ, Hall DE, Flier LA, Gehlsen KR, Turner DC, Carbonetto S, Reichardt LF (1990) A neuronal cell line (PC12) expresses two beta 1-class integrins-alpha 1 beta 1 and alpha 3 beta 1 -that recognize different neurite outgrowth-promoting domains in laminin. Neuron 5:651-662.

Yarnitzky T, Volk T (1995) Laminin is required for heart, somatic muscles, and gut development in the Drosophila embryo. Dev Biol 169:609-618.

Yurchenco PD, Furthmayr H (1984) Self-assembly of basement membrane collagen. Biochemistry 23:1839-1850.

Yurchenco PD, Tsilibary EC, Charonis AS, Furthmayr H (1985) Laminin polymerization in vitro. Evidence for a two-step assembly with domain specificity. J Biol Chem 260:7636-7644. 